\title{
Five Root Canals for a Maxillary First Molar Tooth - A Case Report
}

\author{
Mohammad Aminul Islam ${ }^{1}$, Md. Shamsul Alam² \\ ${ }^{1}$ MS student, ${ }^{2}$ Professor \& Chairman, Department of Conservative Dentistry \& Endodontics, Bangabandhu Sheikh Mujib Medical University, \\ Dhaka.
}

\begin{abstract}
:
This case report represents assessment and management of a maxillary left first molar tooth containing five root canals by endodontic treatment. In this case Mesiobuccal 2 (MB2), Mesiopalatal (MP) and Distobuccal (DB) canals were missed as well as very poor obturation at palatal and mesiobuccal1(MB1) canal during previous treatment history. Three mesiobuccal (MB1, MB2, and MP), DB and palatal canals were identified and endodontic retreatment was done followed by final restoration. This case provides an evidence of variations in the root canals of the mesiobuccal root of maxillary first molar tooth. Complete clinical and radiographic examination and adequate knowledge of the morphology of this kind of teeth is necessary for successful clinical outcome.
\end{abstract}

Key Words: Maxillary first molar, Five root canals, Endodontic Treatment.

[BSMMU J 2012; 5(1):61-64]

\section{Introduction:}

Both external \& internal anatomy of a tooth is an important aspect of root canal treatment. Failure to detect and treat the second MB2 canal system will result in a decreased long-term prognosis. ${ }^{1}$ The main reasons for endodontic failure are apical percolation and presence of micro organisms caused by incomplete instrumentation, inadequate cleaning, insufficient canal obturation and presence of untreated canals ${ }^{2}$. Unusual root and root canal morphology associated with molar teeth have been recorded in several studies in the literature. ${ }^{3,4}$ The maxillary first molar is the largest tooth in volume and one of the most complexes in root and canal anatomy ${ }^{5}$. In a literature review, the morphology of the MB root of 8399 maxillary first molar teeth was assessed in 34 studies where two or more canals were present in $56.8 \%$ in average of all studies and one canal in $43.1 \%$. And single apical foramen was $61.6 \%$ while two apical foramina were $38.3 \%{ }^{3}$ The distobuccal and palatal root was reported in 14 studies included 2576 teeth where the common root canal system configuration of the DB root canal was single $98.3 \%$ and two canals $1.7 \%$, and the single apical foramina was present $98 \%$ of the time as well as the palatal root with single canal $99 \%$ and single apical foramina $98.8 \%$ respectively. ${ }^{3}$ Also some case reports have shown few anomalies like four rooted maxillary first molar presenting mesiobuccal, distobuccal and two palatal root and each root containing single canal also five rooted with two $\mathrm{MB}$, one $\mathrm{DB}$ and two palatal and each root containing single canal. ${ }^{6}$ Three

Address for Correspondence: Mohammad Aminul Islam, MS student, Department of Conservative Dentistry \& Endodontics, Bangabandhu Sheikh Mujib Medical University, Dhaka. splitted palatal canals in a single palatal root as well as single $\mathrm{MB}$ and $\mathrm{DB}$ canal in corresponding root. ${ }^{7}$ Three roots with 6 canals contain two $\mathrm{MB}$, single $\mathrm{DB}$ and three palatal canals. ${ }^{8}$ Two MB canal and a single $\mathrm{C}$ shaped canal form due to fusion of $\mathrm{DB}$ and palatal canal ${ }^{9}$. And also very rarely single-rooted maxillary first molar with a single canal. ${ }^{10-11}$ In one study ${ }^{9}$ shows $0.09 \%$ and another study ${ }^{12}$ shows $0.3 \% \mathrm{C}$ shaped canal in maxillary first molar tooth only.

The mesiobuccal root of the maxillary first molar contains a double root canal system more often a single canal, in most studies. ${ }^{3}$ Two or more canal system in MB root shows higher incidence like Sert $\mathrm{S}^{13}$ 93.5\%, Thomas ${ }^{14} 73.6 \%$, Acosta $^{15} 71.6 \%$, Stropko ${ }^{16} 73.2 \%$, Neaverth ${ }^{17}$ 80.3\%, Nasonowitz ${ }^{18} 64.6 \%$. Some case published regarding to three or more canals in MB root canal system of maxillary first molar tooth. Richard ${ }^{19}$ and Favieri ${ }^{20}$ found $3 \mathrm{MB}, 1$ DB and 1 Palatal canal in maxillary first molar tooth. N Adanir $^{21}$ cited about a four rooted maxillary first molar where MP root contain 2 canals and rest of MB, DB and palatal roots have single canal.

\section{Case report:}

A 31 years old female patient was referred to the department of Conservative Dentistry \& Endodontics at Bangabandhu Sheikh Mujib Medical University (Dhaka, Bangladesh) for better management of upper left second premolar and first molar tooth. At that time, the patient's complaints about inability to enjoy taking food at left side of the jaw. She also reported about mild to moderate pain at several times as well as pain during bite. She gave a previous history of dental treatment at her residence area on tooth 
25 (upper left second premolar) \& 26 (upper left first molar) at two years back. On clinical examination, neither fistula nor oedema was observed. The tooth 25 had a gross proximal caries with occlusal filling and shows exaggerated response of thermal test. The tooth 26 was tender during percussion with no thermal response $\&$ the coronal restoration was not perfectly done. And the periapical radiograph showed thickened periodontal ligament and radiolucent area around the root apex. Also the tooth 26 showed damaged pulpal floor due to previous faulty access opening as well as very poor obturation of the MB and Palatal root canals while DB was untreated. The tooth 25 suggests late stage of chronic pulpitis and the tooth 26 suggest chronic periapical periodontitis. As a result, there was no alternative better option to treat without endodontic treatment of both 25 and 26 .

Local anaesthesia was given and the operative field was isolated for the tooth 26 (left maxillary first molar). After removal of the remaining coronal restoration and prepation of the access cavity, exploration of the root canal entrances revealed 3 canals in the MB root, 1 canal in the $\mathrm{DB}$ root and 1 canal in the palatal root. Where the canal orifices of the MB1 \& MB2 were closer with same apical foramen and the orifice of the MP was far and in between mesiobuccals \& Palatal canal with isolated apical foramen. The MB2, MP and DB was untreated previously. After exploring the five canals, MB2, MP and DB was negotiated with \#10, \#8 and $\# 10 \mathrm{~K}$ files and the under obturated gutta percha was removed from the MB1, Palatal canal with the aid of $\mathrm{H}$ file.

Then the workong length of the tooth was determined radiographically based upon the initial radiograph (Fig-1). Here, The \# $15 \mathrm{H}$ file was used on MB1, \#15 K file on MB2, $\# 15 \mathrm{H}$ file on MP canals as well as the \#20 K file was used on $\mathrm{DB}$ and $\# 25 \mathrm{~K}$ file was on palatal canal respectively (Fig-2). Apical preparation of the MB1 \& MB2 with \#35 H file at $18 \mathrm{~mm}$ working length, and MP with $\# 30 \mathrm{H}$ file at $16.5 \mathrm{~mm}$ working length. The DB and palatal canal was prepared with \#35 H file \& \# $45 \mathrm{H}$ file respectively at the working length of $19.5 \mathrm{~mm} \& 21.5 \mathrm{~mm}$. After chemo mechanical preparation, the canals were flushed with $2.5 \%$ sodium hypochlorite, then dried and filled with calcium hydroxide as an intracanal medication. Root canal access was sealed with zinc oxide eugonol cement. After 7 days, the canals were emptied and the patency of the canals is rechecked with master apical file. Then the canals are copiously flushed with $2.5 \%$ sodium hypochlorite and dried with paper point. Then master gutta percha cone were selected for each canal and all the canals were filled with Sealer 26 (Dentsply, Brazil) using lateral condensation technique. After a temporary coronal restoration, a final radiograph was taken to confirm the competences and extension of root canal filling (Fig-3). The permanent coronal seal was done by crown prosthesis. Then up to six months follow up visit, the patient was evaluated clinically where there was no tenderness to percussion with no sinus tract or any sign of periodontal disease or infection and the tooth was functional.

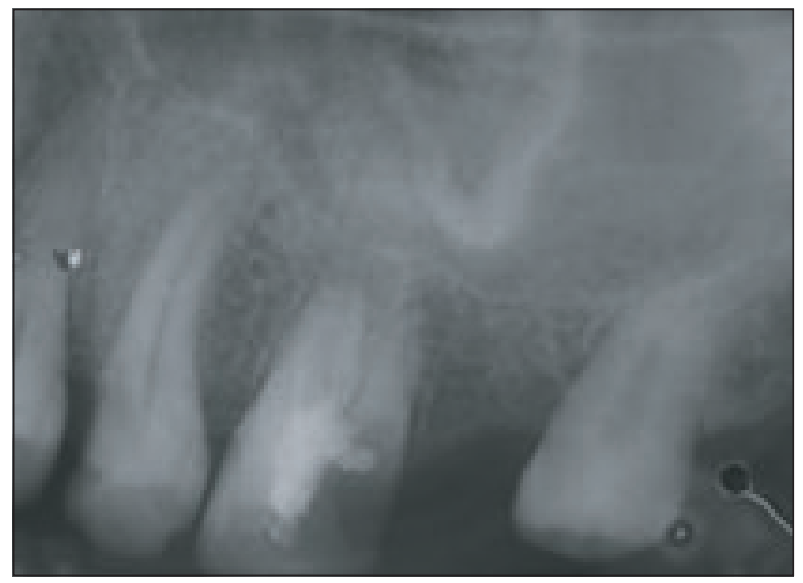

Fig-1: Intraoral pariapical radiograph (Pre operative)

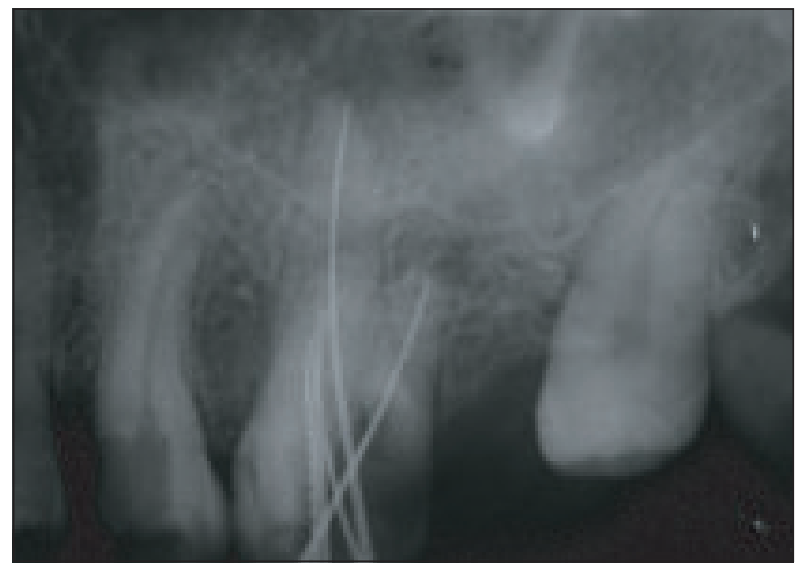

Fig-2: Intraoral pariapical radiograph (Per operative)

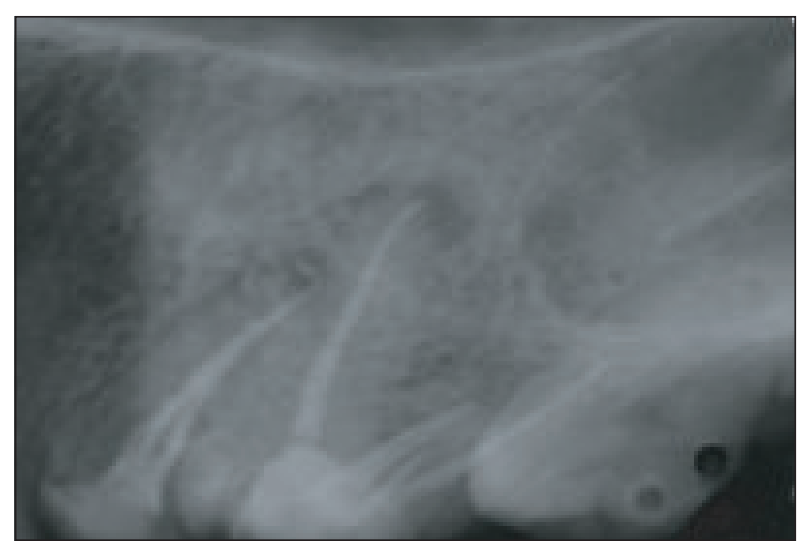

Fig-3(a): Intraoral pariapical radiograph (Post operative) 


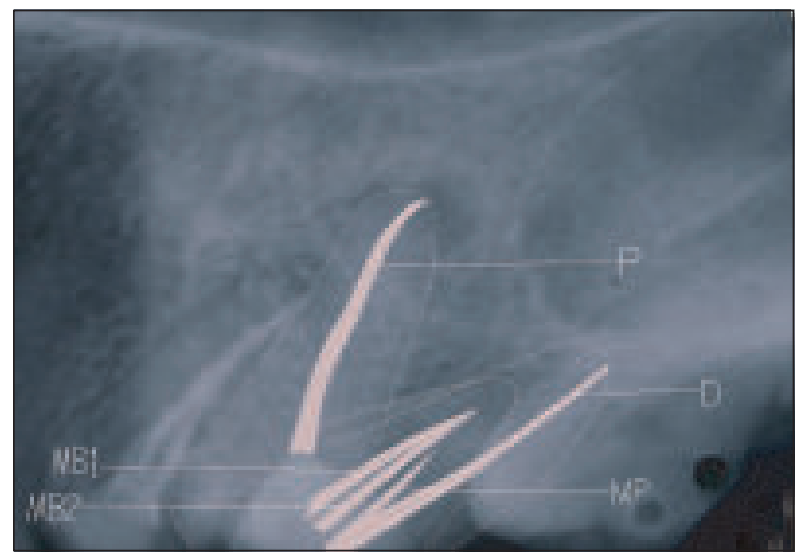

Fig-3(b): Intraoral pariapical radiograph (Post operative)

\section{Discussion:}

Despite the current high success rate achieved in endodontic treatments, the MB root is associated to considerable number of failures due to difficulty in locating and filling the second or third MB canals ${ }^{22,23}$. Clinical experience and histological studies revealed that the MB2 or the MP is commonly located within the developmental groove between the MB1 and palatal canal. To locate the MB2 or MP root canal systems, the clinician should prepare the access cavity mesially at expense of the mesial marginal ridge. As well as to prepare straight line access and to eliminate the pulpal roof.

Anatomically the MB canals and related isthmus aspects of the root canal system lie closer to the external furcal side concavity. A single MB canal is oval and wider buccolingually, two or three canals are more circular. Generally a concavity exists on the distal aspect of the MB root, which makes the wall very thin. ${ }^{5}$ So, all the MB canals specially MB2 and MP must be prepared more conservatively and carefully to avoid future fracture or strip perforation.

Less variation was found in the distobuccal and palatal root representing single canal. The palatal root is often curves buccally at the apical one third which may not be obvious on a standard radiograph. from its orifice, the palatal canal is flat, ribbon like and wider in mesiodistal direction. The distobucal root is conical and from its orifice, the canal first is oval and then becomes round as it approaches the apical third. The incidence two canals in the MB root canal system of maxillary first molar tooth is higher $(60.5 \%)$ in laboratory studies in compare with clinical studies $(54.7 \%)$ on an average. ${ }^{3}$ But interestingly the incidence of location of a two canal system in clinical studies appears to be increasing with routine use of the
SOM and other aids during the modified endodontic access opening procedure. ${ }^{16,24,25}$ So dental practitioner should utilize maximum use of diagnostic aids to find missing canals though in these case the five canals were identified with naked eye using a canal explorer with anatomical guidance after creating straight line access. Now a days, the commonly used canal finding aids are canal explorers, magnification, dye, multiple obliquely angled radiographs, dental operative microscope, wear loupes, fibre optic hand piece, piezoelectric ultrasonic unit, computed tomography etc. but the most important factor to find missing canal is to create a complete access opening and assembling proper internal and external anatomy of that tooth.

\section{Conclusion:}

Inability to find and treat the extra canal which is usually very common in mesiobuccal root of maxillary first molar may cause treatment failure. But a proper clinical guide line and every effort from the clinician may be helpful to find and treat extra canal successfully.

\section{References:}

1. Wolcott J, Ishley D, Kennedy W, Johnson S, Minnich S. Clinical investigation of second mesiobuccal canals in endodontically treated and retreated maxillary molars. $J$ Endod 2002;28:477-9.

2. Siqueira JF Jr., Rocas IN. Clinical implications and microbiology of bacterial persistence after treatment procedures. J Endod 2008;34: 1291-301.

3. Blaine, William and Cecilia. Root and root canal morphology of the human permanent maxillary first molar: A literature review. J Endod 2006;32:(9) 813-21.

4. Flares et al. Analysis of the internal anatomy of maxillary first molars by using different methods. $J$ Endod $2009,35:(3): 337-342$.

5. Vertucci, Haddix, Britto: Ch.7, Tooth Morphology and Access Cavity preparation. Cohen, Hargreaves editors: Pathways of the Pulp, 9th ed., Mosby Yearbook Co., 2006.

6. Barbizam JV, Ribeiro RG, Tanomaru Filho M. Unusual anatomy of permanent maxillary molars. J Endod 2004;30:668-71.

7. Wong M. Maxillary first molar with three palatal canals. $J$ Endod 1991;17:298-9.

8. Maggiore F, Jou YT, Kim S. A six-canal maxillary first molar: case report. Int Endod $J$ 2002;35:486-91.

9. De Moor RJ. C-shaped root canal configuration in maxillary first molars. Int Endod J 2002;35:200-8.

10. Francisco et al . Single-rooted maxillary first molar with a single canal: endodontic retreatment. Oral Surg Oral Med Oral Pathol Oral Radiol Endod 2008;106: e66-e68. 
11. C. Wang \& K. Prasad. Single Rooted Maxillary First Molar: A Rare Case. People's Journal of Scientific Research. Vol. 4(1), Jan. 2011,68-70.

12. Yang ZP, Yang SF, Lee G. The root and root canal anatomy of maxillary molars in a Chinese population. Endod Dent Traumatol 1988;4:215- 8 .

13. Sert S, Bayirli GS. Evaluation of the root canal configurations of the mandibular and maxillary permanent teeth by gender in the Turkish population. $J$ Endod 2004;30:391-8.

14. Thomas RP, Moule AJ, Bryant R. Root canal morphology of maxillary permanent first molar teeth at various ages. Int Endod J 1993;26:257-67.

15. Acosta Vigouroux SA, Trugeda Bosaans SA. Anatomy of the pulp chamber floor of the permanent maxillary first molar. $J$ Endod 1978; 4: 214-9.

16. Stropko JJ. Canal morphology of maxillary molars: clinical observations of canal configurations. J Endod 1999;25:44650 .

17. Neaverth EJ, Kotler LM, Kaltenbach RF. Clinical investigation (in vivo) of endodontically treated maxillary first molars. $J$ Endod 1987; 13: 506-12.
18. Nosonowitz DM, Brenner MR. The major canals of the mesiobuccal root of the maxillary 1 st and 2nd molars. $N Y J$ Dent 1973;43:12-5.

19. Richard g. Beatty. A five-canal maxillary first molar. Journal of endodontics. 1984:10(4):156-157.

20. Favieri, Barros,Campos. Root Canal Therapy of a Maxillary First Molar with Five Root Canals: Case Report. Braz Dent $J$ (2006) 17(1): 75-78.

21. N Adanir. An unusual maxillary first molar with four roots and six canals: a case report. Australian Dental J 2007; 52: (4):33335 .

22. Vertucci FJ. Root canal anatomy of the human permanent teeth. Oral Surg Oral Med Oral Pathol 1984;58:589-599.

23. Fogel HM, Christie WH, Peikoff MD. Canal configuration in the mesiobuccal root of the maxillary first molar: a clinical study. J Endod 1994;20:135-137.

24. Buhrley LJ, Barrows MJ, BeGole EA, Wenckus CS. Effect of magnification on locating the MB2 canal in maxillary molars. $J$ Endod 2002;28:324-7.

25. Sempira HN, Hartwell GR. Frequency of second mesiobuccal canals in maxillary molars as determined by use of an operating microscope: a clinical study. J Endod 2000;26:673-4. 